\title{
INTERVIEW WITH ABIGAIL SAGUY
}

\section{INTERVIEW CONDUCTED BY:}

\author{
EMILY JONES \\ University of Kansas
}

Dr. Abigail Saguy is a professor of Sociology at UCLA who specializes in Cultural Sociology, Gender, Sociology of Law, Political Sociology, Comparative Sociology, Health Policy, and Qualitative Methods.

JONES: So I hope this is not too much of a contentious first question.

SAGUY: Okay, go ahead.

JONES: As a non-fat person, have you noticed that this gives you legitimacy to the study of fat, with the medical community, or conversely, kept you from gaining full entré into fat acceptance circles?

SAGUY: Okay so, yes and no. So I'm going to take the fat entré first because that was you know, when I first started attending research you know the first thing I did, was that I attended a convention for the national association for the advancement of fat acceptance, NAFTA meeting, in 2001, the summer of 2001. So I was seven months pregnant at the time, and I thought, I felt like I was huge, before going to these meetings, but I immediately when I got there realized that I was not. I was just pregnant and it's not the same, it's not perceived the same. But even that, even my pregnant belly, spending just an afternoon with all of these NAFTA members I looked at myself in the mirror and I looked like a skinny girl with a pimple on her stomach. And I felt insignificant, which is interesting you know because we're so inundated with images of very thin women who are airbrushed and you don't really see the equivalent of larger women or just a variety of women getting the same treatment, the same beautiful clothes and the airbrushing etc. 
So we tend to always compare ourselves to those very thin images no matter what your weight is, you feel too heavy. But it was interesting to me how quickly my perspective shifted being in this woman with women who were equally extreme. I mean these were not average sized women. You know models are in the lowest one or two percent, these women are in the highest one or two percent. The women who belong to NAFTA are typically not people with a BMI of 25 or even 30 , they are more likely to have a BMI of 40 . So anyway what was interesting to me is that my impression shifted. And when I first got in there I couldn't really distinguish and everyone looked the same. And then I saw differences and saw that that body type is a beauty body and looked at myself and felt insignificant and kind of...

JONES: You were kind of having a backlash of insecurity based on your surroundings?

SAGUY: Yeah. I mean that became the normal. It didn't take very long for that to become the normal.

JONES: Your term "insignificant" really captures that.

SAGUY: Yeah and it captures the fact that our valuing of weight, how we perceive, the value we give to it really is socially constructed and it can shift. So but to get back to your original question, I was worried about this, you know, how am I going to be received I was hoping that maybe being pregnant, it's silly right in hindsight, but maybe it would give me a little entré. But I was worried, would I be seen as an outsider, and it was the opposite. In that several people said to me, "Oh it's really good that you as a thin person are doing this research. Because they'll listen to you." And you know that really struck me, and it struck me also as just a sign of how early this movement is, that you know, it hasn't, it wasn't seen as a liability, on the contrary it was like okay someone who people will listen to. And then absolutely in terms of when I spoke to obesity researchers, most of whom were male. They were thin, they were you know, not even just upper middle class, but many of them just high upper class elite, you know from the best schools and from old money and all the rest. Going in there I even had one say to me, there was an 
assumption that I had to be on their side, I had to understand what they were talking about, because of my body size. And so they just assumed that I didn't have an ax to grind. So I got this in France, I mentioned to you that I got a Master's degree in France after doing my BA, I was studying the French and U.S. women's movement from the seventies. And actually another woman said to me, "How can you study the women's movement and be objective as a woman, you're clearly... you're biased." And I thought, "Oh so men are the only people who can study the women's movement?" It just seemed so bizarre to me.

JONES: It almost seems like a cop out way to critique someone, you know all the controversy that was around Alice Goffman's book, and it became an idea of who can speak for whom. So I think you'll get that question any time you have a contentious research that is going against the norm.

SAGUY: Yeah so you know at one point too, the publicist at UCLA felt the need to point out in this press release that I was petite, not just that I was petite, but that I was a mother of two. And I said what's this about? This is really odd you know, what does this have to do with anything? And she says oh well you know I just want to make sure that they don't see you as some kind of crazy person.

JONES: Like a crazy activist or...

SAGUY: Yeah. So the fact that I was petite, the fact that I was a mother you know gave me credibility. Glen Gaser who I interviewed who is a researcher, he's a physiologist who wrote a book called Big Fat Lies. In 1997 it came out, so an early, before Paul Campos' book the Obesity Myth. One of the first books to really challenge the idea to show that the science doesn't show that being heavy is unhealthy. The editor said to him that it was good that he was tall and thin and that the editor said he wouldn't have published it otherwise, because he would have been dismissed as having an ax to grind. So this is absolutely....

JONES: It's a very interesting part of doing research, where when you are like the community you seem to understand the community 
in a different way, but then you don't have legitimacy to the outside world.

SAGUY: But yeah, I think a claim could be made, and I certainly, and I definitely think that there's, you know I have a different perspective based on my own embodiment. But I was always very much welcomed and embraced by the fat acceptance community and never dismissed as not getting it. And I have had it from the medical community too. And what I was going to say is that the actual reality of my embodiment doesn't prevent people because I'm a fat person with an ax to grind. So you know if they don't see me and I don't say anything about my own weight, people have do and have assumed that I must be a bigger person. I published a piece in the Washington post, it's online, and there are over 500 comments most of which I did not read. A few people forwarded their comments to me in my personal email but several of them said, you know well it's clear that she's just making excuses for her own weight and you know didn't bother to.... you know.

JONES: So the sociology of medicine, some of the research shows that de-implementation can be much more difficult than implementation strategies, even when new data shows that there is no need for the current medical technology. In what ways do you hope that the conversation in which you are engaging in leads to either a de-implementation or maybe rather an implementation of other medical technologies different than gastric bypass? Because you were saying in your talk the solution seems to be that medical doctors seem to just want to hand out gastric bypass. So because ideological change can be hard, how can we affect the medical conversation with your argument in order to de-implement gastric bypass or implement some other medical technology?

SAGUY: Yeah. I mean it's difficult because the medical profession is a profession it needs to make money you know, and they want to be able to offer something clinical. And my view is that the problem isn't weight you know, and so that's going to, there's not going to be a, I don't have an alternative clinical option, so that's going to leave the doctors without anything to offer. And that's not in their professional interest right, in terms of their own power and their own 
financial interests. So I don't think that medicine is going to really kind of self-regulate in this way. I think that we, and the other thing is that I think we really need to shift the conversation and we need to be talking more about anti-fat stigma and discrimination. Because as long as it is socially so painful to live in this world, that there's so much discrimination and stigma all of the time, people are going to be looking for exits and they're going to be really vulnerable to promises of exits from that identity. And especially from medical authority. And you know it's not just the gastric bypass surgeries, it's also just the main stream dieting, it just doesn't work. It ends up for most people making them heavier in the long term and it can also make them sick, it can mess up their metabolism. But there's you know people want to lose weight not for their health primarily they want to lose weight because they don't want to be discriminated against. So unless we address that weight discrimination and stigma, and you know there are different ways of doing that, and people are doing some of this work. I think some of the work has to be cultural right, people, you were talking about Amy Schumer, that kind of work having people question the sort of stuff you see in fashion with a wider varieties of bodies being seen as beautiful, the way we talk to our children about embracing diversity of body types, so that people feel more empowered to make different decisions.

JONES: Would there be anything to be gained from getting allies from the medical community?

SAGUY: Absolutely and there is a movement within the medical community it's very strong within in the eating disorder community that really sees the negative side of the fat stigma and it's called the health at every size movement. And there are doctors who are invested, there are researchers such as I mentioned earlier, and what they are doing is saying let's not focus on weight, let's focus on how do we make people healthier, how do we take care of their health, at whatever size they are, and just pushing that. And certainly exercise is really, really important and there are all sorts of studies that show that there are just so many health benefits from relieving stress to sleeping better to all of the lab work. 
JONES: Yeah I liked your point yesterday that exercise, you may not actually lose weight but you'll gain all of these benefits, so if we had the conversation about, if the end goal is not always weight loss

SAGUY: Then I think that would help us get a healthier population, it doesn't mean it's going to be easy, there's lots of barriers to exercising anyway, but that should be our goal. You know our goal should be let's try to get people exercising even 20 minutes a day, even 20 minutes a day 5 times a week would be huge, huge improvement, but not make it about weight loss, which is going to be counterproductive to health. I think there's lots of room for improvement in the way we produce and distribute food yeah but these are issues about nutrition and they're issues about workers' rights, there's issues about the environment, and I think we do ourselves a disservice to frame it about weight. Sometimes we're looking in the right place but for the wrong reasons. I mean I think we have issues. We could do much better in terms of food production and distribution. And our priorities and what we're subsidizing, but these are public health crises of their own, they don't need to be, they're not issues because of their effect on people's weight, they're issues because they have direct effects, not only on health but on the environment and on workers lives you know, the livelihood of agricultural workers, these are real issues, the kinds of pesticides that agricultural workers are being exposed to, which incidentally some believe is the cause of the weight gain, it's not what people are eating but exposure to chemicals that's messing up people's metabolism. But again, like I think those are just symptoms of underlying problems, it's the underlying problem.

JONES: If you could please outline, given your work on frames and discourse around fat, how we can more explicitly link the feminization of fat to the degradation of it, and how can that message lead to a bolstering of framing fat as a civil rights issue?

SAGUY: oh interesting, so I talked about this yesterday in terms of, you know the feminization of fat, it can go both ways, for men definitely becoming very fat very soft you know separate from being big, you know being big and muscular is coded as masculine. But being soft in particular places, you know the pectoral region this 
term man boobs is very evocative of how fat on men in the wrong places is feminizing. And being feminized is always degraded I mean gender is a hierarchy you know well, and you know the feminine is subordinated to the masculine, but for men this devaluing. But for women being fat can also be, in our culture because we sort of talked about over breakfast that most places in the world being fat is desirable for women and it's a way in which men first as fathers and then as husbands can store their wealth on women's bodies, the trophy, the visible trophy of their success in places where food is scarce particularly it's a sign of status. But women in our culture are supposed to you know, not be too big, not take up too much space, not throw their weight around right. And so in being big, also in showing appetite which is often implied by the big body, you know someone who's big must have a wild appetite and not just for food but maybe for other things like SEX!

JONES: Right that's also a coded racial thing that happens.

SAGUY: Right absolutely. And so that can be perceived as a failed femininity not as a surplus of femininity but as a lacking, lacking in the feminine qualities of restraint, and being demure, serving others and others desires rather than your own desires and clamping down your own desires.

JONES: So given that, would reframing the acceptance of all different sizes in women, would that bolster fat as a civil rights issue if we could shift the degradation of fat, would that make more acceptance of women in our society?

SAGUY: Yeah I don't know that it would because I don't think there's a lot of openness right now to concerns of gender discrimination, I think that we're at a moment that is seen as illegitimate particularly if we're talking about white women, so I think framing it more about race is potentially more powerful and there's some ways that I do this also in the book, and in my talk yesterday when I often think expressing fat phobia or negative sentiment about fat people is often code for saying negative things about working class and people of color. But you know there is a tradition of talking about fat as a feminist issue within feminist 
circles so there in those circles I think that it can be important and it remains important but it might not help the wider culture because feminism remains a challenging concept for a lot of people. But within feminist circles it's not obvious right, there's a lot of selfproclaimed feminists who are very fat phobic, and in their own lives and how they see the world. And so it's actually part of the challenge as whereas you'd think that feminist would be natural allies they haven't historically embraced this issue. Any talk about weight is focused on the weight of women and girls who aren't really fat but who think they are.

JONES: And I wonder if that's also a class divide in feminists

SAGUY: I think it is, this issue is very classed, and one of the things that are happening when people express negative sentiments about fat people is class bias, and you know also in terms of culture and what people are eating. It's always been that way, where it's always been that whatever the elites are doing is considered the best thing to do and when you know earlier in the $20^{\text {th }}$ century it was eating white bread right and not all of this unrefined stuff and the grains and the grits and the oatmeal was seen as lower class and colored right, sometimes African American but sometimes Irish or Italian and there was a lot of mistrust, and so now the elite eat kale and quinoa.

JONES: Which is what, a lot of impoverished people in the world, that's what they eat!

SAGUY: Right but now that the elites are eating kale and quinoa that becomes the ideal food and if you're not eating it there's something wrong with you and we need to educate you. But it's just another way of imposing social control.

JONES: Would it be helpful to frame fatness or even the inability to keep weight down as a marker of social stress? So I know that we were talking, you talked in your talk and people in the audience were having questions for discussion about why do the doctors weigh us? Why do they care about our weight? But would it be helpful to frame fatness or the inability to keep weight down as a marker of social 
stress if we could use weight as a proxy for social stress, would that be helpful for this conversation?

SAGUY: I think we need to be careful when we're using weight as a proxy for anything because I think it's a crude measure but certainly, I mean I'm not saying, I think the way that we're weighed immediately, and in such a public way, it's difficult for a lot of people and that it would be worthwhile for the medical profession to be a bit more self-reflexive about that, at least to think about it, you know, is it necessary every single time for when someone comes in, can a physician just eyeball the person and see if they look like they've gained a lot of weight or lost a lot of weight, like do you we need to do this...I mean like maybe if they see something that looks disturbing, then they weigh them, but not make it the very first thing you do. Because it can be traumatic for people but certainly there is a lot of research, we know that when the human organism as well as other mammals are stressed we release cortisol and that this can lead to weight gain, particularly in the abdomen where it's most harmful. We know that stress also makes people crave dopamine that you can find in high sugar and high fat, you know we know all of this. So I think we could definitely think about that but I also worry about any kind of automatic pathologizing of the fat body and saying oh here's someone's who's fat, they must be under a lot of stress. You know, you can have that conversation but I think we need to be talking about stress and thinking about environment with all of our patients and some patients will have the opposite, will lose a lot of weight from stress and it's having the same negative effect. But I think in general too we need to be thinking more about how our health is affected by things like, I mean we tend to individualize stress too right but the most interesting literature I know on stress talks about like stress that comes from lack of autonomy and lack of power and being in a dominated position. So like that's not like, you need to do more meditation. That's like we need to think also about the workplaces and inequality and the structure of power. And we don't think about this enough you know. Like does your doctor ever ask you when you go in, what's your social friendship network like? You know how often do you go out, who are your friends, when you're sad who do you talk to, do you feel supported? Are there people who can understand you, who can empathize with you, but 
these are really important things for health. Instead we're just saying, how many glasses of wine do you drink a week, how are you eating, wearing a seatbelt, that's important but you know, you don't even always get that a lot of times it's just let's look at your weight, what are you eating, these very individualized things.

JONES: So my last question is, you started to allude to it earlier, but is there any benefit in dissecting the American relationship compared to the French type of relationship, social meals, the time given to meals, the ingredients, the emphasis on local sustainability, or do you think that obfuscates the framing further given your research showing that awareness of stigma still might blame the victim because we still might think of individual choices.

SAGUY: I think we should also be talking about how we eat, but not because we're fat because we snack all day, which you know I think there's some truth to that, but that, I wouldn't want to make it about fat. I just think the way that we eat is not as pleasurable as it could be. You know, and I think pleasure and sociability is important for health. I think that we're not, the way, I'm appalled at how, what we teach our children about eating, so I've said that my kids have been in schools in France and they've been in schools in the U.S. and my kids are slow eaters and my son you know when he was originally started in kindergarten you know they give him 20 minutes to eat his lunch. And he can't, it's not healthy I don't want him scarfing everything down. So he's not done with his lunch and he's told that he can finish his lunch sitting on a bench watching his friends play. So like what are we teaching our kids about food? Well we're teaching them that it's fuel, they should be quick, it's not, you know, we're not teaching them what they learn in France. So when they go to France they first of all they have a full, it's a canteen, it's not really a cafeteria, it's self-serve but it's a four course meal, they need to, I think they can skip one thing but they need to taste from all of the others, there's always some bread, there's a first course, in France it's an entrée, which is usually some kind of salad or a vegetable, raw vegetable. Then there's a main course. Then there's a cheese or yogurt course, and then there's a dessert. And the dessert is usually a piece of fruit and maybe like once a week they'll get like a slice of pie or something. But the main course also, it has some 
protein it has some starch it has a vegetable. There's not a lot of this short order cooking, what do you like, there's so such thing as a children's meal which you know is the chicken tenders, you know you eat regular food that adults would eat. And then you sit down and you're expected to sit there for an hour and have conversation with the other kids, to use a knife and fork, to put your napkin on your lap and it's like, what are you learning in that context? Well you're learning sociability, you're learning that food is a pleasure, you're learning that you're supposed to eat a variety of different foods. And then, then they have a half hour to play. They have an hour and a half break in the middle of the day. And it's you know, the kids who are in the childcare, which begins when they're infants, they're also getting exposure to lots of vegetables and different foods and it makes the parents job so much easier because it's not like they have to undo everything that was done during the day. And I think you know, if you're satisfied at your meal and you learn to eat good foods, real foods as opposed to chips and fake foods, then you're less likely to snack and there's some respect right, there's some holiness to the meal time. And so I would love for us, I think that that also becomes like a metaphor for life. That life should be savored that we need to take time, that we need to socialize, we should also be taking vacation, and we should be breathing.

JONES: We have a completely different structure in the U.S. and it's not just our food culture it's our work culture.

SAGUY: Right and we talk about the macro or micro nutrients of the food as opposed to you know....

JONES: Yeah. It's very scientific and alienated

SAGUY: We treat it as fuel. And then you know you have people who are part of the foodie culture but it's a very elite space and even those people I know many of them and they'll have like some special meals and some food but then like just a lot of on the go eating.

JONES: Well hopefully we could have a cultural shift! Thank you so much for sitting down and talking to me. 